\title{
Evaluación de PCR en tiempo real en el diagnóstico de leucosis enzoótica bovina en una raza local de Panamá
}

\author{
Villalobos-Cortés, A.I. ${ }^{1}$; Gonzalez, R. ${ }^{1}$, Castillo, H. ${ }^{1}$, y Jaén, M. ${ }^{2}$
}

'Laboratorio de Análisis y Biología Molecular Aplicada. IDIAP. Panamá.

${ }^{2}$ Laboratorio Salud Animal. IDIAP. Divisa, Panamá.

\section{PaLABRAS ClaVe}

Biotecnología.

Salud animal.

Razas locales.

Diagnóstico.

Ganadería.

\section{RESUMEN}

El objetivo de este trabajo fue evaluar la prueba de RT-PCR, para detectar el virus de leucosis enzoótica bovina y compararlas con las pruebas de nPCR y AGID en 42 animales de la raza Guaymí de 5 regiones de Panamá. La prueba de AGID identificó el menor número de animales positivos (52\%) comparada con la $\mathrm{nPCR}(71 \%)$ y PCR en tiempo real, RT-PCR (76\%). Cuatro animales positivos a la prueba de AGID fueron negativos a la prueba de nPCR y dos animales positivos a esta misma prueba fueron negativos a la RT-PCR. 11 de los 20 animales negativos por AGID dieron positivo a nPCR y 12 de los 20 animales negativos a AGID fueron positivos a RT-PCR. Respecto a las pruebas moleculares, de los 12 animales que resultaron negativos a la prueba de $\mathrm{nPCR}$, cinco resultaron positivos a la RT-PCR y de los 10 animales negativos a RT-PCR, 3 resultaron positivos a $\mathrm{nPCR}$. La sensibilidad del $\mathrm{nPCR}$ respecto a AGID fue de $82 \%$ mientras que la especificidad fue de $40 \%$. La prueba de concordancia entre pruebas fue de $k=0.316$, considerada débil mientras que la sensibilidad del RT-PCR respecto a la AGID fue de $91 \%$ con una especificidad de $40 \%$; la prueba de concordancia entre ambas pruebas fue de $k=0.222$ considerada también débil. La técnica de RT-PCR se presenta como una alternativa viable dentro del grupo de técnicas para el diagnóstico del virus de la leucosis enzoótica bovina, particularmente en un eventual programa de control y su erradicación en centros de conservación de razas criollas donde se requiere mantener un estricto control de la salud animal.

\section{Evaluation of real time PCR in the diagnosis of bovine leukemia virus in a local breeds from Panama}

\section{SUMMARY}

\section{AdDITIONAL KEYWORDS \\ Biotechnology. \\ Animal health. \\ Local breeds. \\ Diagnosis. \\ Livestock.}

\section{INFORMATION}

\section{Cronología del artículo.}

Recibido/Received: 01.10.2019

Aceptado/Accepted: 23.01.2020

On-line: 15.01 .2020

Correspondencia a los autores/Contact e-mail:

villalobos.axel@gmail.com
The objective of this work was to evaluate the RTPCR test, to detect the bovine enzootic leukosis virus and compare them with the nPCR and AGID tests in 42 animals of the Guaymi breed from 5 regions of Panama. The AGID test identified the lowest number of positive animals (52\%) compared to $\mathrm{nPCR}(71 \%)$ and real-time PCR, RT-PCR (76\%). Four animals positive to the AGID test were negative to the $\mathrm{nPCR}$ and two animals positive to this same test were negative to RTPCR. 11 of the 20 AGID negative animals tested positive for $n P C R$ and 12 of the 20 AGID negative animals tested positive for RT-PCR. Regarding molecular tests, of the 12 animals that were negative for the nPCR, five were positive for RT-PCR and 10 animals negative for RTPCR, 3 were positive for $n P C R$. The sensitivity of $n P C R$ to AGID was $82 \%$ while the specificity was $40 \%$; the concordance test between nPCR and AGID was $k=0.316$, considered weak while the sensitivity of RT-PCR with AGID was $91 \%$ with a specificity of $40 \%$; the concordance test between the two tests was $k=0.222$ also considered weak. The RTPCR technique is presented as a viable alternative within the group of techniques for the diagnosis of bovine enzootic leukosis virus, particularly in an eventual control program and its eradication in conservation centers of Creole races where it is required to maintain a strict control of animal health.

\section{INTRODUCCIÓN}

El virus de la leucosis bovina es un retrovirus exógeno, causante de la Leucosis Enzoótica Bovina (LEB), la enfermedad neoplásica más común del ganado a nivel mundial, exceptuando a la mayoría de los países europeos que han instaurado programas de erradicación (Beyer et al., 2002; Rodríguez et al., 2011; Moratorio et al., 2013). La infección se transmite horizontal- mente mediante, la transferencia de células infectadas por contacto directo, ingestión de leche y mediante insectos hematófagos (Ferrer et al., 1979; Gillet et al., 2007). También se ha demostrado la transmisión vertical (madre-hijo) vía uterina (Van derMaaten et al., 1981; Romero et al., 1983; Lassauzet et al., 1991). El $30 \%$ de los animales infectados pueden presentar una linfocitosis persistente (PL), particularmente por incre- 
mento de linfocitos B. Entre 1 y $5 \%$ de los casos puede manifestarse como linfoma de células $B$, después de un prolongado periodo de latencia (Panei et al., 2013) causada por una represión del virus (Kettman et al., 1980), como una estrategia de evasión a la respuesta inmunológica, permitiendo el desarrollo de masas tumorales (Merimi et al., 2007).

La técnica de inmunodifusión en gel de agar (AGID), ha sido un indicador de infección por BLV durante décadas pasadas y sigue siendo la prueba oficial de referencia para el transporte de animales dentro del país, aunque tiene un bajo costo, actualmente se ha demostrado ser una prueba menos sensible comparada con técnicas más recientes como ELISA y la PCR (Buehring et al., 2003). La prueba de AGID no puede distinguir entre los anticuerpos adquiridos pasivamente (calostrales) y los adquiridos mediante infección natural (Hugh-Jones, 1992). Otra desventaja que presentan estas técnicas es que no pueden detectar animales jóvenes infectados o animales en estadios tempranos de la infección. La prueba de PCR ha sido utilizada para la detección temprana del LEB en animales menores de seis meses (Agresti et al., 1993; Kelly, 1993) y evita reacciones falsas positivas causadas por transferencia pasiva de inmunoglobulinas a través del calostro. Otra ventaja radica en la capacidad para detectar el virus en animales inmunotolerantes (Fechner et al., 1996). La PCR en tiempo real (RT-PCR) presenta ventajas en comparación con la PCR en punto final y PCR anidada (nPCR), como menor tiempo en la ejecución del ensayo, pues se elimina el tiempo en que se realiza la electroforesis para la visualización de los productos de la PCR y permite el diagnóstico en un mayor número de muestras, igualmente disminuye la posibilidad de contaminación cruzada, ya que es innecesaria la manipulación de los productos de la PCR y presenta mayor sensibilidad, además el costo de los reactivos que van disminuyendo cada año (Kubista et al., 2006). En la actualidad la OIE en su manual de enfermedades terrestres tiene como métodos analíticos aprobados para el diagnóstico de la BLV, la PCR, AGID y ELISA, aunque las más recomendadas y validadas son las dos últimas mencionadas (OIE, 2018). El objetivo de este trabajo fue evaluar la prueba de RT-PCR, para la detección del virus de leucosis enzoótica bovina y compararlas con las pruebas de nPCR y la AGID en el contexto de la conservación de razas localmente adaptadas como la raza Guaymí, y la integración de un plan sanitario de prevención y control en centros de conservación de razas criollas en riesgo de extinción.

\section{MATERIAL Y MÉTODOS}

Se utilizaron las tres técnicas de diagnóstico para la detección del virus de (LEB) en 42 bovinos criollos Guaymí de 5 regiones de la República de Panamá (Calabacito, 9; Chiriquí, 8; El Coco, 11. El Ejido, 7; Río Hato, 7) desarrollados en los laboratorios de Análisis y Biología Molecular Aplicada (LABMA) y en los, laboratorios de Agrobiotecnología y Salud Animal del Instituto de Investigación Agropecuaria de Panamá. Se obtuvieron $5 \mathrm{ml}$ de sangre en tubos con anticoagulante EDTA de muestras de 33 hembras y 9 machos de cinco fincas propiedad del IDIAP; mediante las técni- cas de AGID, nPCR y RT-PCR. Se utilizó el kit marca PORQUIER® IDG de Leucosis Bovina, para realizar el diagnóstico de AGID, en el laboratorio de Salud animal del Centro de Investigación Agropecuaria del IDIAP, Divisa. La extracción del ADN se realizó mediante el reactivo comercial, QuickExtract ${ }^{\mathrm{TM}}$ de Epicentre al aislado de PBMC, el cual consta de la aplicación de 500 ul del producto, un pase de vórtex por 15 segundos y calentar a $65^{\circ} \mathrm{C}$ por 6 minutos, posteriormente aplicar vórtex y calentar a $98^{\circ} \mathrm{C}$ por 2 minutos. Con este procedimiento se logró obtener una concentración promedio de 218 ng/ul de ADN genómico. Para aplicar la técnica de nPCR, se aplicó el protocolo desarrollado por Villalobos et al. (2017). Con el ADN extraído se aplicaron las dos técnicas de PCR, la nPCR y RT-PCR. Con la técnica de $\mathrm{nPCR}$, se utilizó una región altamente conservada del gen env que codifica la proteína de la cápside gp51. Se empleó el protocolo modificado de Beier et al. (2001). La primera reacción se realizó a un volumen final de $30 \mu \mathrm{l}$ que contenía 70-100 ng de ADN, $0.5 \mathrm{mM}$ de cada oligonucleótido Forwardenv 5032 (5'-TCTGTGCCAAGTCTCCCAGATA-3') y Reverse-env 5608r (5'-AACAACAACCTCTGGGGAGGGT-3'), $0.2 \mathrm{mM}$ de cada dNTP, 1X de tampón PCR, 1.5 mM MgCl2 y 1U de Taq DNA Polimerasa. En la segunda reacción se utilizó como ADN molde 3 $\mu l$ del producto de PCR de la primera amplificación, las mismas concentraciones de los otros reactivos y los oligonucleótidos Forward-env 5099 (5'CCCACAAGGGCGGCGCCGGTTT-3') y Reverse-env 5521r (5'GCGAGGCCGGGTCCAGAGCTGG-3'). El perfil térmico incluyó una etapa de desnaturalización inicial a $94^{\circ} \mathrm{C}$ durante 9 minutos, seguido por 35 ciclos de $95^{\circ} \mathrm{C}$ durante 30 segundos, $62^{\circ} \mathrm{C}$ durante 30 segundos y $72^{\circ} \mathrm{C}$ durante 1 minuto, para terminar con una extensión final a $72^{\circ} \mathrm{C}$ durante 4 minutos. En la segunda reacción las condiciones de amplificación fueron las mismas, excepto que la temperatura de anillamiento se aumentó a $70^{\circ} \mathrm{C}$ (Licursi et al., 2003). La identificación de los animales positivos a la presencia del provirus se hizo mediante un analizador de fragmentos de electroforesis capilar marca QIAgen $®$. La presencia de una banda de 444 pares de bases se tomó como indicativo que el animal era positivo al provirus, utilizando un marcador QX DNA SizeMarker 25-500bp (50 ul) v2.0 de QIAgen®. El protocolo de RT-PCR se basó en el gen pol del virus (Heenemann et al., 2012) de LEB mediante el kit 2x QuantiTecProbe PCR master mix ajustado a un volumen final de 25ul, 10uM de cebador BLV-pol-s Forward (5'-CCCTGGCCTACTTTCAGACC-3'), 10uM BLV-pol-as Reverse (5'-CTTGGCATAAGAGCTTAAGGCC-3'), 9.25uM BLV polprobe (5'- TTGACTGACAACCAAGCCTCACCT-3'). El extremo 5 'de BLV polprobe se etiquetó con 6-carboxifluoresceína (FAM) y el extremo 3 ' fue etiquetado con el agujero negro quencher 1 (BHQ1). La reacción se llevó a cabo usando un sistema de PCR en tiempo real con el siguiente perfil de temperatura: $95^{\circ} \mathrm{C}$ por 15 minutos, seguido de 45 ciclos de $94^{\circ} \mathrm{C}$ a 15 segundos de desnaturalización y $60^{\circ} \mathrm{C}$ por 60 segundos de anillamiento/extensión. Los datos de fluorescencia se recolectaron durante el paso de anillamiento/extensión en el canal FAM-Green. Se consideraron positivas las muestras con valores de $\mathrm{Ct}$ entre 22 y 39 (Henneman et al., 2012). Para determinar 
los parámetros de sensibilidad, especificidad y concordancia (valor kappa) entre las pruebas de nPCR, RT-PCR y AGID se utilizaron tablas de contingencia (2x2) empleando el programa computacional WinEpi 2.0 (de Blas et al., 2006). Todos los análisis se realizaron con un nivel de confianza de $95 \%$.

\section{RESULTADOS Y DISCUSIÓN}

En Panamá las razas locales Guaymí y Guabalá, recuperaron su valor, cuando se logró demostrar su singularidad, estructura genética y su relación con otras poblaciones bovinas de Iberoamérica (Villalobos et al., 2010; Delgado et al., 2011; Martínez et al., 2012), en el marco del proyecto Biobovis de la Red Conbiand, previamente establecida como Red CYTED XII- H (Delgado 2002). Este logro llevó a la reformulación del proyecto de conservación y uso de las razas criollas Guaymí y Guabalá en Panamá, iniciado décadas antes sin obtener mayor impacto que el de mantener un solo núcleo de conservación en la región occidental de país, con el riesgo de perderlo por efecto de la endogamia o la posible incidencia enfermedades. Es así como este proyecto de conservación implicaría la ejecución de un estricto programa sanitario que evite el contagio de las enfermedades más importantes en el país, particularmente la leucosis enzoótica bovina, por tanto, era relevante para el mismo, presentar los primeros trabajos de diagnóstico molecular de BLV con RT-PCR en Panamá y compararlos con dos técnicas utilizadas actualmente.

De los resultados obtenidos en la prueba AGID (oficial en la República de Panamá), se detectó un menor número de animales positivos (52\%) comparada con la PCR anidada, nPCR (71\%) y PCR en tiempo real, RTPCR (76\%) (Figura 1).

Cuatro animales positivos a la prueba de AGID resultaron negativos a la prueba de nPCR y dos animales positivos a esta misma prueba fueron negativos a la RT-PCR. Además, de los 20 animales negativos por AGID, 12 dieron positivo a nPCR y de los 20 animales negativos a AGID 12 resultaron positivos a RT-PCR. Respecto a los resultados entre las pruebas moleculares, de los 12 animales que resultaron negativos a la prueba de nPCR, cinco resultaron positivos a la

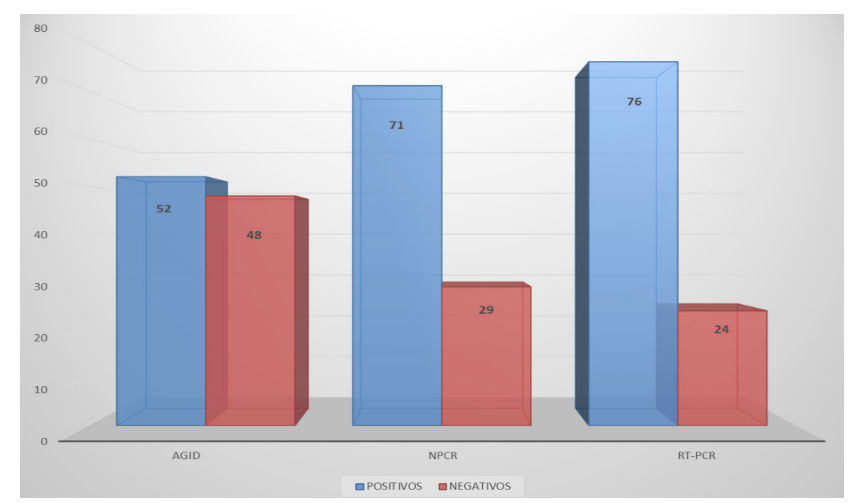

Figura 1. Comparación resultados de las pruebas de AGID, nPCR y RT-PCR de leucosis enzoótica bovina en la raza Guaymí. (Comparison test results for AGID, nPCR and RT-PCR of bovine enzootic leukosis in the Guaymí breed).
RT-PCR y de los 10 animales negativos a RT-PCR, 3 resultaron positivos a $\mathrm{nPCR}$ (Tabla I).

La prueba de concordancia entre AGID vs RT-PCR fue de $k=0.316$, considerada débil mientras que la prueba de concordancia entre AGID vs nPCR fue de $\mathrm{k}=0.222$ considerada también débil. La prueba de concordancia entre nPCR vs RT-PCR fue de k=0.509 considerada moderada.

La sensibilidad del nPCR respecto a AGID como prueba de referencia fue de $82 \%$ mientras que la especi-

Tabla I. Comparación de resultados entre AGID, nPCR y RT-PCR con los respectivos valores de kappa en el diagnóstico de BLV (Comparison of results between AGID, nPCR and RT-PCR with the respective kappa values in the diagnosis of BLV).

\begin{tabular}{lccc}
\hline & + AGID & - AGID & TOTAL \\
+ RT-PCR & 20 & 12 & 32 \\
- RT-PCR & 2 & 8 & 10 \\
Kappa = 0.316 & 22 & 20 & 42 \\
+ nPCR & AGID & - AGID & TOTAL \\
- nPCR & 18 & 12 & 30 \\
& 4 & 8 & 12 \\
Kappa $=0.222$ & 22 & 20 & 42 \\
& & & \\
+ RT-PCR & 27 & - nPCR & TOTAL \\
- RT-PCR & 3 & 5 & 32 \\
& 30 & 7 & 10 \\
\hline KapPa & 0.509 & 12 & 42 \\
\hline
\end{tabular}

Kappa $=0.509$

ficidad fue de $40 \%$. La sensibilidad del RT-PCR respecto a la AGID fue de $91 \%$ con una especificidad de $40 \%$. La sensibilidad de RT-PCR vs nPCR fue de $90 \%$ con una especificidad de $58 \%$. Los valores reportados son similares a los de Felmer et al. (2006) cuando compara nPCR vs AGID (sensibilidad 96\%, especificidad 45\% y $\mathrm{k}=0.45$ ), sin embargo, son más bajos que los reportados por Lamas et al. (2012) al comparar nPCR, RT-PCR y utilizando AGID como prueba de oro.

En el presente estudio, realizado en Panamá, se introduce un método más, rápido, de mayor sensibilidad y especificidad y con menos contaminación para la detección del provirus BLV en PBMC de ganado potencialmente infectado (Henneman et al., 2012) particularmente en una raza localmemnte adaptada incluida en núcleos de conservación, donde se requiere un tratamiento diferenciado en que se espera obtener una mayor certeza de la infección del virus en sangre y mantener los hatos libres. En contraste con la mayoría de los ensayos de PCR anidada donde se utiliza el gen env o gag del virus (Felmer et al., 2004; Villalobos et al., 2017), este trabajo se enfocó en secuencias conservadas del gen pol, adecuadas para un ensayo en tiempo real 
basado en exonucleasa 5' (Heeneman et al., 2012). La técnica de RT-PCR descrita en el presente trabajo tiene capacidad de detectar entre 1 a 5 moléculas de la secuencia objetivo (Hennemann et al., 2012) por lo que son de gran utilidad en los servicios de vigilancia veterinaria, particularmente en animales cuyos porcentajes de infección del provirus en la fase asintomática son menos del 1\% en PBMC (Gillet et al., 2007). También como herramienta en situaciones con ganado cuya carga genética incluye alelos del complejo mayor de histocompatibilidad clase II (BoLA-DRB3.2) asociados a resistencia al virus y animales infectados por BLV con baja o indeterminada respuesta humoral (Mirsky et al., 1998; Juliarena et al., 2007; Dube et al., 2009).

Se ha demostrado recientemente que poblaciones criollas como la raza Blanco Orejinegro presentan frecuencia de alelos favorables a la resistencia del virus como el alelo BoLA-DRB3*0902 o BoLA-DRB3*1701 (Úsuga-Monroy et al., 2018). La presencia de estos alelos les permite mantener bajos títulos de anticuerpos contra las proteínas gp51 y p24 y una carga proviral baja, evitando el contagio entre animales, (Juliarena et al., 2009; Juliarena et al., 2016). En un estudio realizado con la población Guaymí y Guabalá en Panamá (Villalobos et al., 2018), se identificaron alelos del BoLA-DRB3*0101, BoLA-DRB3*1101 y BoLA-DRB3*3001, mismos que fueron reportados por Yoshida et al. (2011) y Nikbakht et al. (2016) como alelos asociados a resistencia a la mastitis y con bajos títulos de anticuerpos contra gp24; otros autores los han reportado también como alelos favorables a resistencia a BLV (Hernández et al., 2018), por lo tanto, en el caso que exista algún animal identificado como positivo, pero con una carga proviral baja, se espera que el riesgo de contagio disminuye significativamente (Juliarena et al., 2017) por lo que sería innecesaria la eliminación de un animal dentro del hato o su sacrificio. Normalmente los programas de conservación se trabajan con números reducidos de animales, cada uno de estos ejemplares tiene un valor muy alto y no es suficiente obtener un diagnóstico positivo de la enfermedad. En este caso se destaca la importancia de incluir en un futuro cercano, la RT-PCR como técnica diagnóstica a elegir y en caso de que sea positivo, determinar la carga proviral, particularmente en razas criollas, incluidas dentro de programas de conservación como la Guaymí y Guabalá.

Este hecho justificaría que los protocolos de diagnóstico molecular de BLV, deben incluirse en un formato anidado o en RT-PCR para obtener resultados con mayor precisión. En relación con los resultados obtenidos entre RT-PCR y nPCR, la diferencia en cuanto a la detección de animales positivos fue mínima (76 vs 71, respectivamente), empero, la ventaja de PCR en tiempo real radica en que es un procedimiento más corto, totalmente automatizado, no se requiere procedimiento post-PCR, la colecta de datos es en tiempo real durante la fase de crecimiento exponencial, mayor rango dinámico de detección, es posible cuantificar el número de copias presentes en la muestra analizada y es más fácil de realizar para pruebas de alto rendimiento. Además, la PCR en tiempo real es menos propensa a la contaminación cruzada (Petersen et al., 2018). En relación con las diferencias obtenidas entre AGID y las
RT-PCR los resultados concuerdan con los reportados por Jimba et al. (2012), la AGID es la prueba estándar en muchos países, no obstante, se ha demostrado que la misma tiene una menor sensibilidad comparada con cualquiera de las pruebas de ELISA, nPCR y RT-PCR (Felmer et al., 2006; Jimba et al.,2012; Villalobos et al., 2017). Aun así, AGID todavía permanece dentro de las pruebas recomendadas en el libro de enfermedades terrestres de la organización mundial de sanidad animal, debido a su buena especificidad, sencilla, fácil de realizar y su utilidad en esquemas de erradicación, sin embargo, tiene baja sensibilidad (OIE, 2018). Por otro lado, en proyectos de conservación, donde existen animales domésticos en riesgo de extinción, se considera que AGID no sería recomendable su uso.

\section{CONCLUSIONES}

La prueba de RT-PCR resultó con mayor sensibilidad en el diagnóstico del virus de la leucosis enzoótica bovina comparada con las otras dos técnicas dentro del presente estudio.

La técnica de RT-PCR se presenta como una alternativa viable dentro del grupo de técnicas para el diagnóstico del virus de la leucosis enzoótica bovina, particularmente en un eventual programa de control y su erradicación

Dentro de los proyectos de conservación de razas criollas como la Guaymí y la Guabalá, se recomienda, evitar el uso de la técnica AGID y utilizar el diagnóstico de BLV, mediante las técnicas previamente evaluadas. Además, sumar el cálculo de la carga proviral con genotipado de gen BoLA-DRB3.2, para reducir las pérdidas de animales positivos y generar un acervo genético de animales resistentes.

\section{AGRADECIMIENTOS}

La Secretaría Nacional de Ciencia y Tecnología de Panamá y al Sistema Nacional de Investigación por el financiamiento en la realización de este trabajo.

\section{BIBLIOGRAFÍA}

Agresti, A., Ponti, W., Rocchi, M., Meneveri, R., Marozzi, A., Cavalleri, D., Peri, E., Poli, G., Ginelli E. 1993. "Use of polymerase chain reaction to diagnose bovine leukemia virus infection in calves at birth". Am J Vet Res,vol 54 no 3, pp 373-8.

Beier, D., Blankenstein, P., Marquardt, O. \&Kuzmak, J 2001. "Identification of different BLV proviruses isolates by PCR, RFLP and DNA sequencing". Berl. Munch. Tieraztl. Wschr,no. 114, pp. 252-256.

Beyer, J., Köllner, B., Teifke, JP., Starick, E., Beier, D., Reimann, I., Grunwald, U. \&Ziller, M 2002. "Cattle Infected with Bovine Leukaemia Virus may not only Develop Persistent B-cell Lymphocytosis but also Persistent B-cell Lymphopenia". J. Vet. Med. B, no 49, pp 270-277

Buehring, GC., Philpott, SM. \&Choi KY 2003. "Humans have antibodies reactive with Bovine leukemia virus". AIDS Res HumRetroviruses, vol. 19 , no. 12, pp. 1105-1113.

De Blas, I., Ruiz-Zarzuela, I. \& Vallejo, A 2006. "WinEpi: Working in epidemiology. An online epidemiological tool". ISVEE 11: Proceedings of the 11 th Symposium of the International Society for Veterinary Epidemiology and Economics, Cairns (Australia), August 6-11 2006. Theme 4 - Tools \& training for epidemiologists: Poster session, 2006; 800 
Delgado, JV 2002. "Conservación de los recursos genéticos animales y Los sistemas de explotación tradicionales dentro Del programa iberoamericano de ciencia y Tecnología para el desarrollo (CYTED)". Arch. Zootec, no 51, pp. 15-23

Dube, S., Abbott, L., Dube, DK., Dolcini, G., Gutierrez, S., Ceriani, C., Juliarena, M., Ferrer, J., Perzova, R. \&Poiesz, B 2009."The complete genomic sequence of an in vivo low replicating BLV strain". Virol J, no. 6, p. 120

Fechner, H., Blankenstein, P., Looman, A., Elwert, J., Geve, L., Albrecht, C., Kurg, A., Beier, D., Marquardt, O. \& Ebner D 1997. "Provirus variants of the bovine leukemia virus and their relation to the serological status of naturally infected cattle". Virology, no 237, pp. 261-9.

Felmer, R., Zúñiga, J.\&Recabal, M 2006. "Comparative study of nested $P C R$, ELISA and AGID tests in the detection of bovine leukaemia virus infection in serum, blood and milk samples". Arch. Med. Vet, vol.38, n.2, pp.137-141.

Ferrer, JF 1979. "Bovine leukosis: Natural transmission and principles of control". Journal of the American Veterinary Medical Association, Schaumburg, vol. 175, no. 12, pp. 1281-1286.

Gillet, N., Florins, A., Boxus, M., Burteau, C., Nigro, A., Vandermeers, F., Balon, H., Bouzar, AB., Defoiche, J., Burny, A., Reichert, M., Kettmann, R., \& Willems L 2007."Mechanisms of leukemogenesis induced by bovine leukemia virus: prospects for novel anti-retroviral therapies in human". Retrovirology, no 4, pp. 18

Heenemann, K., Lapp, S., Teifke, J., Fichtner, D., Mettenleiter, T. \& Vahlenkamp, T 2012. "Development of a Bovine leukemia virus polymerase gene-based real-time polymerase chain reaction and comparison with an envelope gene -based assay". J VET Diagn Invest, vol. 24, no. 4, pp. 649-55.

Hernández, D; Muñoz, J. \& Álvarez, L "Dinámica de la Leucosis Bovina en el ganado criollo Hartón del Valle en infección natural". Arch. Zootec. no 65 vol 25, pp 365-373.

Hernández, D., Montes, D., y Álvarez, L 2018. "Association of BolaDRB3.2 Alleles with Enzootic Bovine Leukosis: Profiles BLV Infection, Persistent Lymphocytosis and Antibody Production in Harton Del Valle Cattle". Indian Journal of Science and Technology, vol 11 , no 24, pp 14 Hugh-Jones, ME 1992. "Serological study in the incidence and prevalence of antibodies to bovine leukemia virus in agar sera". Can J Comp Med, no 48, pp. 422-424.

Jimba, M., Takeshima, S., Matsumoto, Y., Kobayashi, N., Matsuhashi, T. \& Aida, JKY 2011. "BLV-CoCoMo-qPCR: comparison of other detection methods for BLV infection and kinetics analysis in experimental transmission of BLV in cattle". Retrovirology, v.8, Suppl. 1, p.A21, 2011. Disponívelem: <http://www.retrovirology.com/content/8/S1/A21>. Acessoem: 10 out. 2011. doi: 10.1186/1742-4690-8-S1-A21.

Juliarena, MA., Gutierrez, SE. \&Ceriani, C 2007."Determination of proviral load in bovine leukemia virus-infected cattle with and without lymphocytosis". Am J Vet Res, no, 68, pp.1220-1225.

Juliarena MA, Barrios CN, Ceriani MC, Esteban EN. "Hot topic: bovine leukemia virus (BLV)-infected cows with low proviral load are not a source of infection for BLV-free cattle". J Dairy Sci., no 99, vol 6, pp 4586-4589.

Kelly, E., Jackson, M., Marsolais, G., Morrey, J. \& Callan, R 1993. "Early detection of bovine leukemia virus in cattleby use of the polymerase chain reaction". Am J Vet Res, no 2, pp. 205-9.

Kubista, M., Andrade, JM., Bengtsson, M., Forootan, A., Jonák, J., Lind, K., Sindelka, R., Sjöback, R., Siögreen, B., Strömbom, L., Ståhlberg, A. \&Zoric, N2006. "The real-time polymerase chain reaction". Molecular Aspects of Medicine, v.27, pp.95-125.

Lassauzet, MLG., Thurmond, MC.,Johson, WO. \& CA Holmberg 1991. "Factors Associated with in utero or periparturient transmission of Bovine Leukemia virus in calves on a California Dairy". Canadian Journal of Veterinary Research, vol. 55, pp. 264-268.

Licursi, M., Inoshima, Y., Wu, D., Yokoyama, T., Gonzalez, E. \&Sentsui, H 2003. "Provirus variants of bovine leukemia virus in naturally infected cattle from Argentina and Japan". Vet. Microbiol, no. 96, pp. 17-23.
Merimi, M., Klener, P., Szynal, M., Cleuter, Y., Bagnis, C., Kerkhofs, P., Burny, A., Martiat, P., Van Den Broeke, A 2007. "Complete suppression of viral gene expression is associated with the onset and progression of lymphoid malignancy: observations in Bovine Leukemia Virus-infected sheep". Retrovirology, no 4, p. 51.

Mirsky, ML., Olmstead, CA., Da, Y. \&Lewin HA 1998. "Reduced bovine leukemia virus proviral load in genetically resistant cattle". Animal Genetics, vol 29, no 4, pp 245-252.

Moratorio, G., Fischer, S., Bianchi, S., Tomé, L., Rama, G., Obal, G., Carrión, F., Pritsch, O.\& Cristina A 2013. "Detailed molecular analysis of complete Bovine Leukemia Virus genomes isolated from B-cell lymphosarcomas". Vet. Res. no 44, p19.

Nikbakht Brujeni, G., Ghorbanpour, R. \& Esmailnejad, A 2016. Biochem Genet, no 54, pp. 194. https://doi.org/10.1007/s10528-0169712-6

OIE. World Organisation for Animal Health. "Manual of diagnostic tests and vaccines for terrestrial animals", Paris, 2018. Disponivelem http:// www.oie.int/en/standard-setting/terrestrial-manual/access-online/ 21 agosto 2019.

Panei, C., Takeshima, S., Omori, T., Nunoya, T., Davis, WC., Ishizaki, H., Matoba, K. \& Aida Y 2013. "Estimation of bovine leukemia virus (BLV) proviral load harbored by lymphocyte subpopulations in BLVinfected cattle at the subclinical stage of enzootic bovine leucosis using BLV-CoCoMo-qPCR". BMC Veterinary Research, no 9, p. 95.

Petersen, MI., Alvarez, I., Trono, KG. \& Jaworski, P 2017. "Quantification of bovine leukemia virus proviral DNA using a low-cost real-time polymerase chain reaction". J. Dairy Sci,no. 101, pp. 6366-6374.

Rodríguez, S., Florins, A., Gillet, N., de Brogniez, A., Sánchez-Alcaraz, M.,Boxus, M., Boulanger, F., Gutiérrez, G., Trono, K., Alvarez, I., Vagnoni, L.\& Willems, L 2011."Preventive and therapeutic strategies for bovine leukemia virus: lessons for HTLV". Viruses, no3, pp.1210-48.

Romero, CH., Cruz, GB\& Rowe CA 1983. "Transmission of bovine leukaemia virus in milk". Trop Anim Health Prod, no 15, pp. 215-218. Úsuga-Monroy, C., Zuluaga, JJy López-Herrera, A. "El virus de la leucosis bovina disminuye la producción y calidad de leche en ganado Holstein". Archivos de Zootecnia. no 67, vol 258, pp. 254-259.

Van Der Maaten, JM., Miller, JM. \& Schimerr MJF. 1981. "In utero transmission of bovine leukemia virus". American Journal Veterinary Research, v.42, n.6, pp.1052-1054.

Villalobos Cortés, Al., Martínez, AM., Escobar, C., Vega-Pla, JL. \& Delgado JV 2010. "Study of genetic diversity of the Guaymi and Guabala bovine populations by means of microsatellites". Livestock Science, vol. 131, pp.45-51.

Villalobos-Cortés, Al., Franco, S., González, R. \& Jaén, M 2017. “Nested polymerase chain reaction ( $\mathrm{nPCR}$ ) based diagnosis of bovine leukemia virus in Panama". African Journal of Biotechnology, vol. 16, no. 11, pp. 528-535.

Villalobos-Cortés, Al. \& S., González, R 2018. "Secuencias del gen BoLA-DRB3.2 de bovinos Guaymí y Guabalá de Panamá" Ciencia Agropecuaria, no. 28, pp. 22-36.

Yoshida, T., Furuta, H., Kondo, Y., \& Mukoyama, H 2011 . "Association of BoLA-DRB3 alleles with mastitis resistance and susceptibility in Japanese Holstein cows". Animal Science Journal, no 83, vol 5, pp. 359-366. doi:10.1111/j.1740-0929.2011. 00972.x 